\title{
Surgical Considerations of the Cystic Duct and Heister Valves
}

\author{
Lucas N. Pina ${ }^{1,2}$ Franca Samoilovich ${ }^{1}$ Sebastián Urrutia ${ }^{1}$ Agustín Rodríguez ${ }^{1}$ Lisandro Alle ${ }^{2}$ \\ Alberto R. Ferreres ${ }^{2}$ \\ ${ }^{1}$ Department of Anatomy, University of Buenos Aires (UBA), Buenos \\ Aires, Argentina \\ 2 Department of Surgery, University of Buenos Aires (UBA), Buenos \\ Aires, Argentina \\ Address for correspondence Lucas Nahuel Pina, MD, Martín de Gainza \\ 453, Dept. “C," AR1405, Ciudad Autónoma de Buenos Aires, Argentina \\ (e-mail: lucasnpina@gmail.com).
}

Surg J 2015;1:e23-e27.

\section{Abstract \\ Keywords \\ - cystic duct \\ - biliary tract \\ - Heister valves \\ - transcystic exploration}

Objectives Heister valves are mucosal folds located on the endoluminal surface of the cystic duct (CD) and were first described by Lorenz Heister in 1732. Their presence could represent an obstacle that impedes transcystic exploration. It has been suggested that the distribution of Heister valves follows a steady rhythmic pattern in a spiral disposition; however, there is no conclusive data to support this claim. The aim of this study was to describe the main characteristics of the $C D$ and Heister valves in adult human cadavers. Methods A descriptive cross-sectional study was performed on 46 extrahepatic biliary tracts.

Results The CD has an average length of $25.37 \mathrm{~mm}$ and diameter of $4.53 \mathrm{~mm}$. The most frequent level of junction was the middle union. Heister valves were present on 32 CDs; in most cases, they were distributed uniformly on the duct and presented an oblique disposition. A nonreticular pattern was the most frequent reticular pattern. The most frequent type of the nonreticular type was the B1 subtype. The most frequent type of distribution was the nonreticular type, particularly the B1 type.

Conclusions The cystic fold could hinder transcystic exploration. The cysticotomy incision should not be determined by the distribution of the fold on the CD. The morphology of the Heister valves does not show evidence of a steady systematic pattern.
Heister valves, also known as spiral valves, are mucosal folds located on the endoluminal surface of the cystic duct (CD). They were described by Lorenz Heister in 1732, ${ }^{1}$ who attributed a valvular function to them. Following this original description, other functions have been assigned to the folds, until Dasgupta and Stringer concluded that the valves constitute a structural device rather than a valvular mechanism. ${ }^{2}$

Exploration of the extrahepatic biliary tract by a transcystic approach can successfully manage cholelithiasis during laparoscopic cholecystectomy. ${ }^{3}$ Anatomical factors like permeability, diameter, and length of the $\mathrm{CD}$ should be taken in consideration before opting for a transcystic approach. ${ }^{4}$ In this manner, Heister valves could also represent an obstacle that impedes a transcystic approach by reducing the lumen of the $\mathrm{CD} .^{5}$

The term spiral valves, used by other authors, suggests that the valves possess a steady rhythmic pattern and are set in a spiral disposition. This claim has been based on the morphology observed on Heister's first diagrams, on corrosion casts of the $\mathrm{CD},{ }^{6}$ and on cholangiography images. ${ }^{7}$ However, there is no conclusive data on this topic.

The references to the anatomy of the Heister valves are scarce; therefore, the aim of this study was to describe the main characteristics of the $C D$ and Heister valves in adult human cadavers. received

July 26, 2015

accepted after revision

October 7, 2015

published online

November 19, 2015
DOI http://dx.doi.org/

$10.1055 / \mathrm{s}-0035-1567879$. ISSN 2378-5128.
Copyright $\odot 2015$ by Thieme Medical Publishers, Inc., 333 Seventh Avenue, New York, NY 10001, USA. Tel: +1(212) 584-4662.
License terms

(요 (1) $\Theta \circledast$ 


\section{Methods}

In Argentina, there is no legislation on academic management of cadaveric tissue, unlike what happens with cadaveric organs for transplantation. In this study, human cadavers from the Department of Anatomy at the University of Buenos Aires were used, under the approval of the Department of Bioethics based on the moral principle of human respect.

A descriptive cross-sectional study was performed on 46 extrahepatic biliary tracts fixed and preserved in $7 \%$ formaldehyde. Thirty-one of them were in situ and 15 were already extracted from the human cadavers before measurements were made.

A midline incision was made in the abdominal wall to expose the peritoneal cavity. The hepatoduodenal ligament and the free border of the lesser omentum were dissected to allow access to the extrahepatic biliary tract. Finally, the common hepatic duct (CHD), the $\mathrm{CD}$, and the left and right hepatic ducts were dissected.

The length and external diameters of the $C D$ were measured. The length of the $\mathrm{CD}$ was considered from the neck of the gallbladder to its confluence with the common bile duct. The characteristics of the $\mathrm{CD}-\mathrm{CHD}$ junction and the side of insertion on the CHD were recorded. The level in which the $\mathrm{CD}$ joined the $\mathrm{CHD}$ was measured by dividing the common bile duct from the left and right hepatic duct junction to the duodenal end of the common bile duct in four equal segments. A middle union was considered when the joint occurred on the second segment of the common bile duct; a joint above or below the second segment was considered a high or low union, respectively (-Fig. 1).

After external characteristics were recorded, a cysticotomy was performed along the longitudinal axis of the $C D$ to expose the Heister valves. The number, distribution, and disposition of the Heister valves were recorded. The endoluminal length of the Heister valves was measured from its origin at the endoluminal surface to its free edge (-Fig. 2 ).

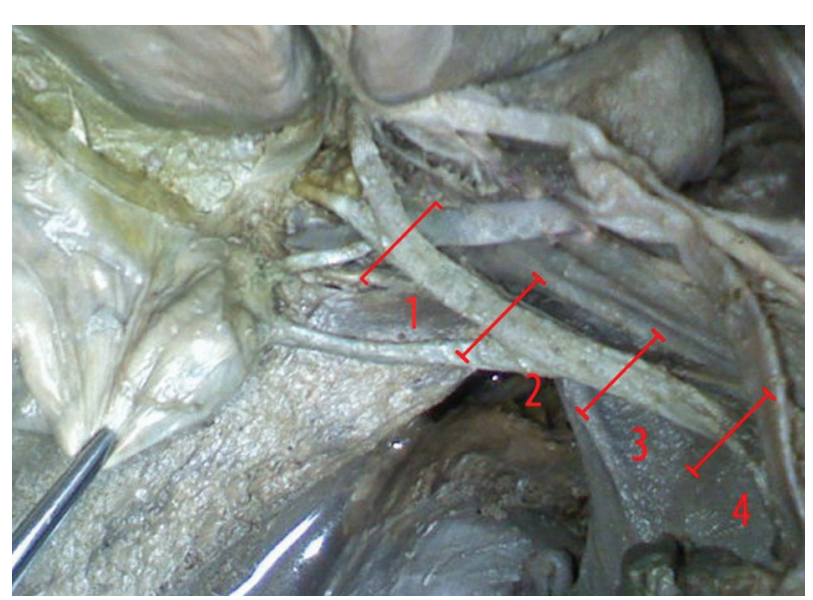

Fig. 1 Division of the extrahepatic biliary tract into four equal sections. The red numbers enumerate the four sections (1 to 4 ) between each red segment.

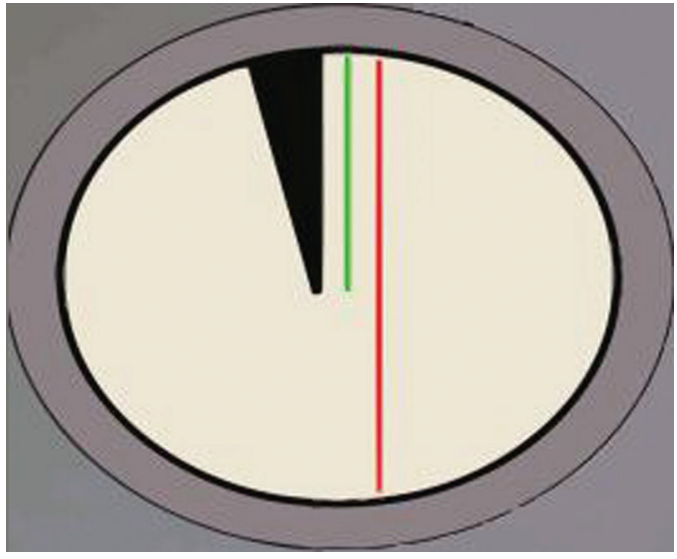

Fig. 2 Relationship between the endoluminal length of the Heister valves (green) and the diameter of the cystic duct (red).

Two types of Heister valve distribution were defined according to its morphology. The first one, a reticular type, presented a nonarranged distribution with honeycomb appearance. The second one, or nonreticular, presented an arranged distribution. The latter type could be divided into two subtypes, a subtype A when the quantity of Heister valves was 3 or more and subtype B when less than 3. Each subtype could be divided into two groups: 1 when the ratio between the endoluminal length and the diameter of the $C D$ was superior or equal to 0.25 and 2 when the relationship was lower than 0.25 (-Table 1).

Finally, a mixture of polyester resin and catalyst (resin 9075 of Noviplast company, Buenos Aires, Argentina) was injected on the lumen of two CDs until the entire gallbladder and $\mathrm{CD}$ were replete. After hardening, the tissue was removed from the finished cast. The endoluminal morphology was recorded along with the prints left by the disposition of the Heister valves.

All measurements were performed with a digital caliper, and all findings were recorded with digital photography.

\section{Results}

The CD measured a median of $25.37 \mathrm{~mm}$ (range 8 to 34) in length and a median of $4.53 \mathrm{~mm}$ (range 2.4 to 8.4 ) in diameter. The characteristics of the CD-CHD junction were studied on 31 extrahepatic biliary tracts. We identified an angular convergence between the $\mathrm{CD}$ and the CHD in 21 cases

Table 1 Classification of the nonreticular distribution type of Heister valves according its quantity and the ratio between the endoluminal length and the diameter of the cystic duct

\begin{tabular}{|l|l|}
\hline $\begin{array}{l}\text { Ration of endoluminal length and } \\
\text { the diameter of the cystic duct }\end{array}$ & $\begin{array}{l}\text { Quantity of } \\
\text { Heister valves }\end{array}$ \\
\hline $1 \geq 0.25$ & $\mathrm{~A} \geq 3$ \\
\hline $2<0.25$ & $\mathrm{~B}<3$ \\
\hline
\end{tabular}




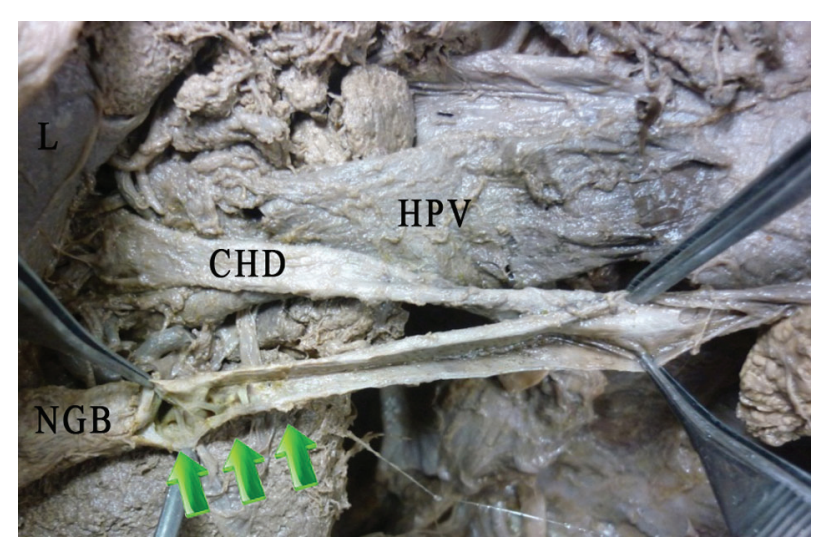

Fig. 3 Anterior view of the endoluminal surface of the cystic duct showing a distal distribution of the Heister valves (green arrows). Abbreviations: CHD, common hepatic duct; HPV, hepatic portal vein; $\mathrm{L}$, liver; NGB, neck of the gallbladder.

(67.74\%), parallel in 5 cases (16.12\%), and straight in 5 cases (16.12\%); none was spiral-shaped. The CD was inserted on the anterior aspect of the CHD in 4 cases $(12.90 \%)$, on the rightsided aspect in 21 cases (67.74\%), and on the posterior aspect in 6 cases (19.35\%). The CD-CHD junction was a middle union in 17 cases (54.83\%); higher and lower unions were observed in 11 (35.48\%) and 3 (9.68\%) cases, respectively.

Heister valves were present in 32 cases (69.56\%) and absent in 14 cases (30.43\%). The median quantity was 3.58 (range 1 to 8 ), with a median endoluminal length of $1.23 \mathrm{~mm}$ (range 0.32 to 2.03 ). Heister valves were distributed uniformly on the full length of the CD in 16 cases (50\%); in 9 cases (28.12\%), they were only present in the proximal end of the CD and in 7 cases (21.87\%) in its distal end. The disposition of Heister valves was oblique in 14 cases (43.75\%) and transverse in 9 cases (28.12\%); in 10 cases (31.25\%), both dispositions were shown (-Figs. 3, 4, 5, and 6).

The reticular morphological pattern was observed in 5 cases $(15.62 \%)$, and the nonreticular pattern was observed in 27 cases (84.37\%). Among the nonreticular patterns, the

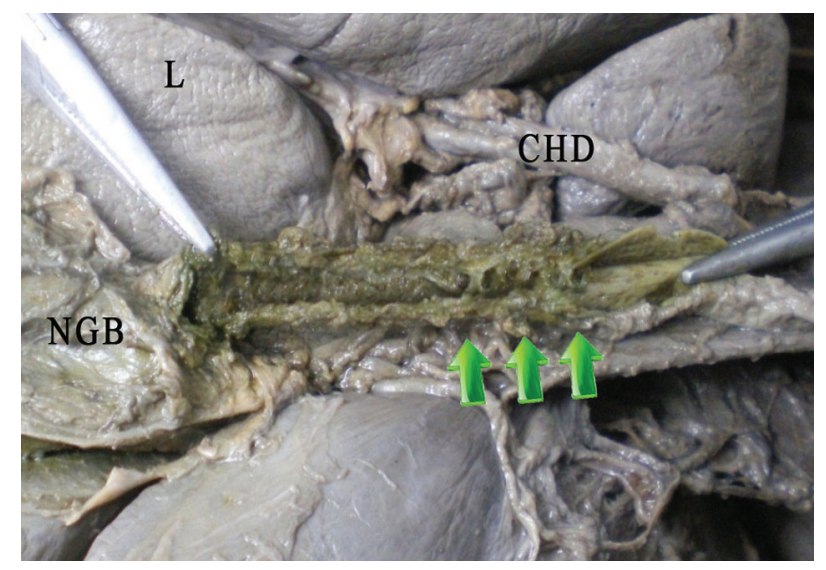

Fig. 4 Anterior view of the endoluminal surface of the cystic duct showing a proximal distribution of the Heister valves (green arrows). Abbreviations: CHD, common hepatic duct; L, liver; NGB, neck of the gallbladder.

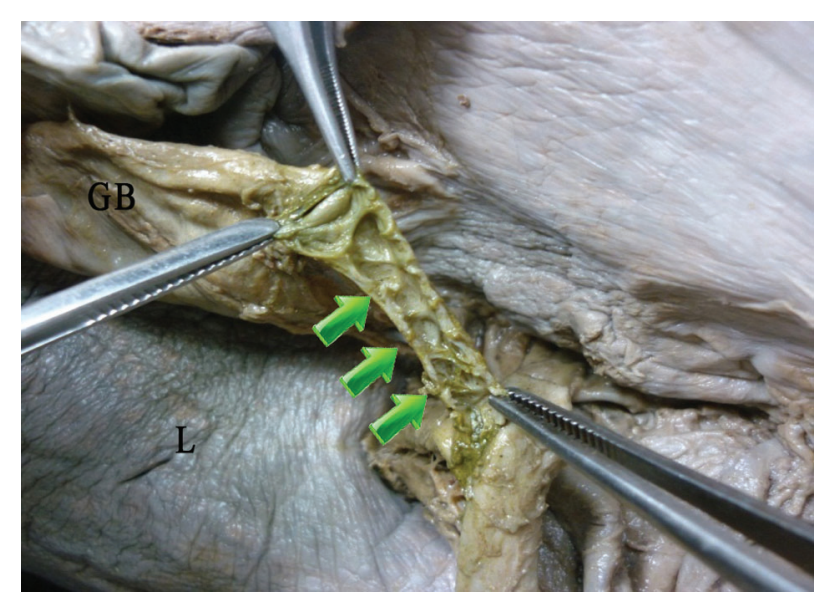

Fig. 5 Anterior view of the endoluminal surface of the cystic duct showing a reticular distribution in all the length of the cystic duct (green arrows). Abbreviations: GB, gallbladder; L, liver.

classification according to the number of valves and the ratio between the endoluminal length of the valves and the $C D$ diameter was the A1 type in 7 cases (26\%), the A2 type in 6 cases (22\%), the B1 type in 8 cases (30\%), and the B2 type in 6 cases (22\%).

Using the casting techniques, we obtained two reliable casts of the endoluminal lumen of the $C D$ with prints of the disposition of Heister valves on its surface. The casts showed the winding morphology of the endoluminal lumen of the $C D$. The prints of Heister valve showed a lack of junction between adjacent fold and an absence of a continuous pattern to suggest a spiral disposition (-Fig. 7).

\section{Discussion}

Since Heister first described the mucosal folds of the $\mathrm{CD}$ as a valvular system, its function has been discussed. Keith believed that the valves prevent collapse of the $\mathrm{CD}$, providing support to its walls. ${ }^{8}$ Mentzer, ${ }^{9}$ Répássy et al, ${ }^{10}$ and Scott and Otto $^{11}$ concluded that the valves may help regulate bile

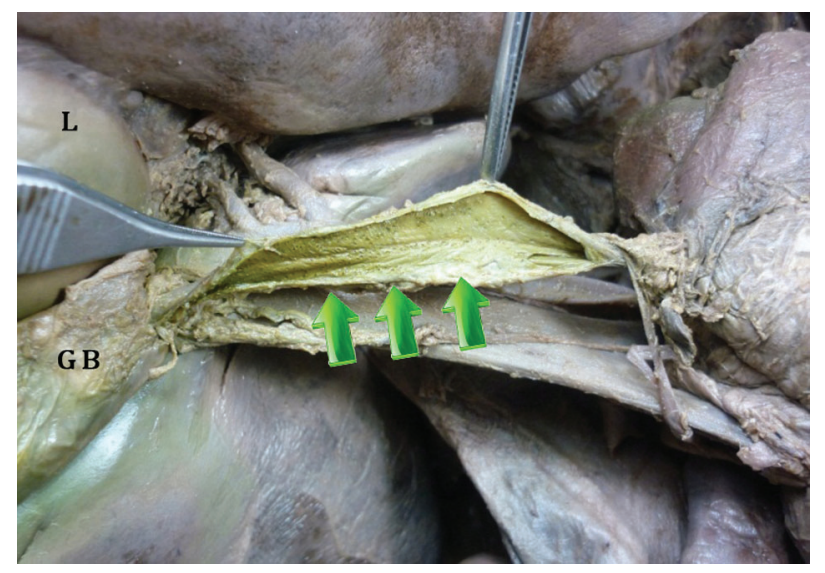

Fig. 6 Anterior view of the endoluminal surface of the cystic duct showing absence of Heister valves in all its length (green arrows). Abbreviations: L, liver, GB, gallbladder. 


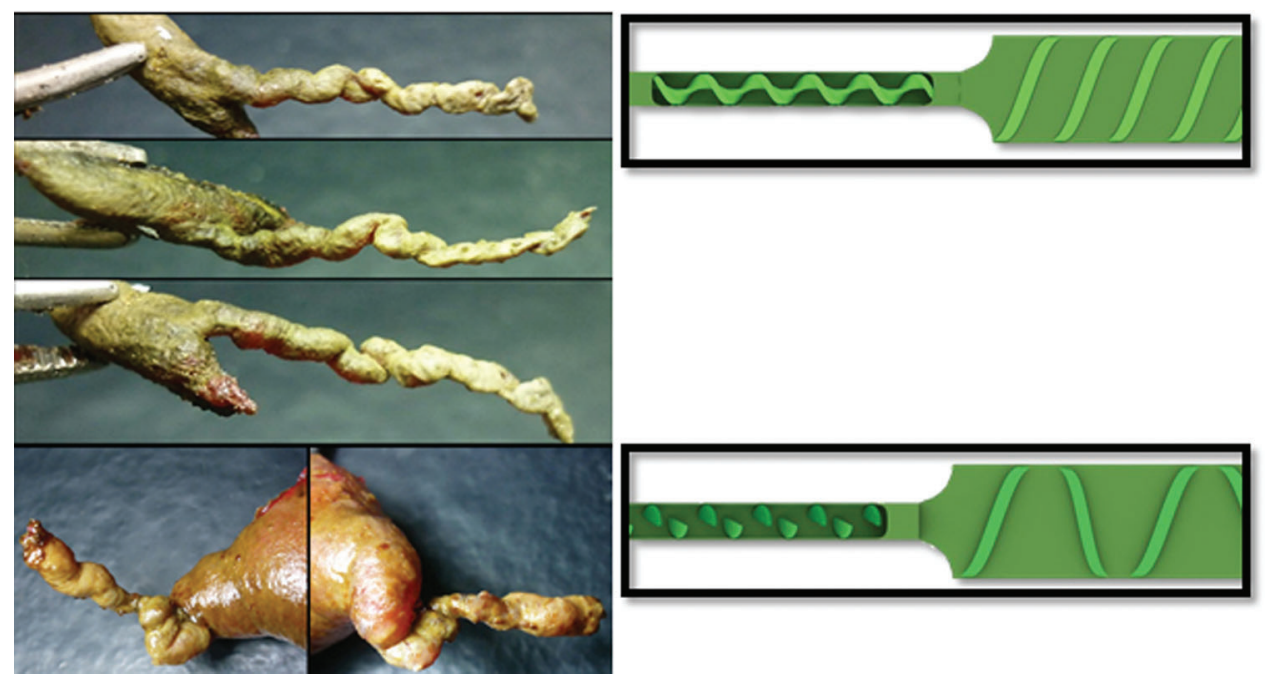

Fig. 7 Polyester resin cast and valve distribution graphic. The cystic duct shows a torsion pattern and prints of the Heister valves' disposition. Error perceptions of a spiral pattern.

passage. Liechtenstein and Ivy denied their valvular function and considered that the valves were a support against pressure changes. ${ }^{12}$ Finally, in 2005 Dasgupta and Stringer concluded that the valves have a primarily structural function. $^{2}$ We suggest that because the valves were absent in 7 cases (22.6\%), they are a nonessential structure for the bile flux.

Transcystic exploration is limited by a small diameter, long tortuous CDs, or numerous gallstones. ${ }^{3}$ There are reports of failures in cholangiography or transcystic exploration because of "unfavorable anatomy" without specific details. Despite the fact that some authors mentioned Heister valves as a possible cause of failure, only Saenz et al reported a failure rate of $6 \%$ attributed to the valves, requiring the use of other techniques like endoscopic retrograde papillotomy. ${ }^{5}$ According to our study, numerous and wide folds as in A1 type or a reticular pattern formed by wide folds distributed uniformly could represent an obstacle in cannulation even when choosing a specific place to perform cysticotomy.

The presence of Heister valves and the technical difficulties involved lead to defining the most appropriate place to perform the cysticotomy. ${ }^{12}$ The position is determined by the amount and the location of the valves (proximal or distal predominance) as well as the larger-diameter segment. In this way, options include incisions performed close to the common bile duct where there is a larger diameter and fewer valves, ${ }^{13,14}$ or close to the gallbladder neck, previously clipped. ${ }^{15}$

The distribution patterns of Heister valves on our study -proximal (16.13\%), distal (16.13\%), and uniform (45.16\%) -suggest that the place of incision of the $\mathrm{CD}$ could not be determined by the amount of proximal or distal valves because we did not find differences between them. To establish the position of $C D$ incision, it is important to have experienced surgeons and visualize directly the larger-diameter segments of the $\mathrm{CD}$.

Heister valves have been also known as spiral valves, although it was not suggested on the first anatomical description. This idea has been supported by Ignatović et al and Bird et al, ${ }^{6,7}$ who based their conclusions on observations of resin casts and cholangiography images of the $C D$. However, studying the disposition of Heister valves in this way could be misleading because images and casts provide a better comprehension of the endoluminal morphology than the disposition of Heister valves. These observations could be inaccurate and subject to an error of perception that gives the illusion of continuity.

According to our study, the lack of junctions between adjacent folds causes the absence of a continuous pattern on the prints of the casts and in the endoluminal surface of the $\mathrm{CD}$. In none of the observed cases did a spiral disposition display a steady rhythmic pattern. Therefore, it is possible that the previous assumptions on the spiral disposition of the valves could have been driven by error in perception based on the Gestalt laws of grouping. ${ }^{16-21}$

Finally, to be in accordance with its real function and morphology, we propose the use of the term cystic folds instead of Heister valves.

\section{Conclusion}

Heister valves are mucosal folds located in the endoluminal surface of the CD. They were found in 32 cases (69.5\%), distributed evenly along all the length of the $C D$ without preference for the distal or proximal ends. The most frequent type of distribution was the nonreticular type, particularly the B1 type. The Heister valve morphology did not show the evidence of a steady rhythmic pattern suggestive of a spiral disposition. Previous assumptions on the spiral disposition of the Heister valves may have been based on errors in perception because of the illusion of continuity that Heister valves and the morphology of the CD suggest. We propose the use of the term cystic folds instead of Heister valves or spiral valves to be in accordance with its real function and morphology. 


\section{References}

1 Heister L. Compendium anatomicum totem rem anatomicam. Vols. 1-2. Nuremberg, Germany: GC Weber; 1732

2 Dasgupta D, Stringer MD. Cystic duct and Heister's “valves". Clin Anat 2005;18(2):81-87

3 Petelin JB. Laparoscopic common bile duct exploration. Surg Endosc 2003;17(11):1705-1715

4 Braghetto IM, Cardemil HG, Diaz JC, et al. Exploración laparoscópica de la vía biliar: ¿cuándo? ¿cómo? ¿dónde? ¿quién?. Rev Chil Cir 2010;62(3):293-300

5 Saenz A, Amador MA, Martinez I, Astudillo E, Fernández-Cruz L. Coledocolitiasis no sospechada: abordaje laparoscópico durante la colecistectomía. Cir Esp 2002;71:68-74

6 Ignjatović D, Djurić B, Zivanović V. Where to incise and/or divide the cystic duct. Acta Chir Iugosl 2002;49(1):99-101

7 Bird NC, Ooi RC, Luo XY, Chin SB, Johnson AG. Investigation of the functional three-dimensional anatomy of the human cystic duct: a single helix? Clin Anat 2006;19(6):528-534

8 Keith A. The nature and anatomy of enteroptosis (Glenard's disease). Lancet 1903;1:631-640

9 Mentzer SH. The valves of Heister. Arch Surg 1937;1:38-53

10 Répássy G, Schaff Z, Lapis K, Marton T, Jakab F, Sugár I. Mucosa of the Heister valve in cholelithiasis: transmission and scanning electron microscopic study. Arch Pathol Lab Med 1978;102(8):403-405

11 Scott GW, Otto WJ. Resistance and sphincter-like properties of the cystic duct. Surg Gynecol Obstet 1979;149(2):177-182
12 Liechtenstein ME, Ivy AC. The function of the "valves" of Heister. Surgery 1937;1:38-53

13 Chamberlain RS, Blumgart LH. Hepatobiliary Surgery. 1st ed. Georgetown, TX: Landes Bioscience; 2001:156-164

14 Barberán WV, Paredesa LF, Barberán DV, Jiménez A. Tratamiento laparoscópico de la litiasis coledociana abordaje transcístico. Revista Facultad de Ciencias Médicas de la Universidad de Guayaquil 2012;15:2

15 Mutter D. Colecistectomía laparoscópica por litiasis vesicular sintomatica. WeBSurg.com 2001;1(2). Available at: http://ecaths1.s3. amazonaws.com/tecnicasquirurgicas1/Colecistectomia.laparoscopica.por.Litiasis.vesicular.Asintomatica.1109366088.pdf. Accessed March 2013

16 Salas CF, Pekolj J. Colangiografíaintraoperatoria. Rev Argent Resid Cir 2009;14(1):8-11

17 Leeuwenberg E, Van der Helm P, Van Lier R. From geons to structure. A note on object representation. Perception 1994; 23(5):505-515

18 Wertheimer M. Gestalt Theory, A Sourcebook of Gestalt Psychology. New York, NY: Humanities Press; 1950:71-88

19 Kanizsa G. Gramática de la visión. Barcelona, Spain: Paidós; 1998: $16-70$

20 Koffka K. Perception: An introduction to the "Gestalt-Theorie". Psychol Bull 1922;19:531-585

21 Koffka K. Principles of Gestalt Psychology. London, UK: Lund Humphries; 1935:161-187 